Citation of this article: Cheng, F., and Lam, D. (2010). How is street life? An examination of the subjective wellbeing of street children in China. International Social Work, 53(3), 353-365.

\title{
How is street life? An examination of the subjective wellbeing of street children in China
}

\begin{abstract}
Street life significantly reduced the street children's SWB. The street children's SWB was lower than those of regular people. The level of self-esteem played a moderating role in their life satisfaction and positive affect. This study shows the significance of providing life necessities and psychological counseling to the street children.
\end{abstract}

Key words: childhood, China, street children, subjective wellbeing 


\section{How is street life? An examination of the subjective wellbeing of street children in China}

\section{Introduction}

Street children are excluded from mainstream society (De Venanzi, 2003). They not only lack access to basic life necessities, but are also frequently discriminated and abused by others (Cheng, 2008; West, 2003). This exclusion against street children imposes a great impact upon the children's psychological wellbeing. Stress and depression are prevalent among the population, particularly when they were compared with normal children. The rates of enuresis, regressive behavior, anxiety, and depression in street children were found much higher than their counterparts in common children (Ayerst, 1999; Donald \& Swart-Kruge, 1994). But is their life totally negative? Studies on street children's psychological status focused mainly on their pathological dimensions. Little attention has been paid to the overall subjective wellbeing (SWB) of street children. How do the children feel towards their life? Such perspective seems to be missing.

To fill the abovementioned research gaps, this study aims to examine the children's subjective wellbeing by investigating their global evaluations of their lives. According to the milestone works of Diener and his colleagues (Diener, 1994; Diener, et al., 1997; Diener \& Suh, 2000), SWB has three main components: life satisfaction, positive affect, and negative affect. And the evaluation of SWB could be done by examining its cognitive dimension (people's conscious evaluative judgments about their satisfaction with life as a whole) and its affective dimension (people's positive affect and negative affect in reaction to their lives at the same time). If one frequently 
experiences a high level of life satisfaction and positive affects, and seldom experiences negative affects such as anger and depression, then it could be said that s/he has a high level of SWB. In contrast, if s/he is seldom satisfied with her/his life and frequently experiences negative affects, then s/he can be said to have a low level of SWB (Diener, et al., 1997).

Predicting factors of SWB have been identified. Income, social support, life events, and self-esteem are believed to be the most common ones. It is reported that income for basic needs plays a key role in influencing people's SWB score. A higher income and better life conditions are more likely to produce a higher SWB than a lower income and poorer life condition. Yet, further studies indicated that economic life condition only functioned at lower levels where basic life needs are not satisfied (Diener, et al., 1997). The adaptation theory posits that people's SWB is affected by the life events they experience. Particularly, new life events, whether positive or negative, may significantly influence peoples' SWB at its very beginning. With the passing time, people may gradually habituate and adapt to their new life circumstances (Diener, et al., 1997). This means that new life events can have a short-term impact upon people's SWB. Other studies found SWB moderately related to peoples' social network. Good social relationship is reported as a prerequisite of high SWB (Biswas-Diener \& Diener, 2006; Diener \& Seligman, 2004; Putnam, 2000). The lower SWB of immigrant adolescents, for example, was found to be caused by the loss of their peer group and reliable parental figures resulting from the immigration-related crisis (Mirsky, 1997). Aside from the aforementioned predicting factors, there is evidence suggesting that peoples' self-esteem has a positive relationship with their SWB (Judge, et al., 2002; Roy, et al., 1995). Obviously, study on the subjective well-being of street children is yet very limited. In China, actually 
no study has been done on the topic. This paper reports the findings of a study launched to explore the situation of street children in one of the largest city of China, Shanghai.

\section{Guiding Hypotheses}

The study was launched to examine the global status of street children's SWB, and to test possible predictors of their SWB. On the basis of the aforementioned theories and knowledge of SWB, the study examined the following four specific hypotheses.

Hypotheses 1: The street children's SWB is below the neutral point on average. As the street children's connection with the mainstream society is basically cut, and they cannot obtain basic necessities in their everyday life, it is logical to assume that the street children's SWB is below the neutral point on average.

Hypotheses 2: The longer the street children wander on the streets, the higher their SWB would be. According to the adaptation theory, street life as a new life event may impose more stress upon new street children. It is hypothesized that street children who have lived in the streets for a longer time might have habituated to the harsh life, condition thus their SWB would improve.

Hypothesis 3: The street children's SWB positively correlates with the social support they have. Social support may help street children to tackle the different kinds of challenges in street life. Thus, it is expected that street children with more social support shall have a higher level of SWB than those with less social support.

Hypothesis 4: The street children's level of self-esteem positively correlates with their 
SWB. It is hypothesized that street children with a higher level of self-esteem would have a higher level of SWB, as the level of self-esteem has been proven to be a predicting factor of other populations' SWB.

\section{Methods}

Sample

Street children are here defined as children aged below 18, who spend most of their time in the streets instead of their homes or schools, with few or no responsible adult's supervision and protection. Given the chaotic and unstable everyday lives of street children, it is difficult to make a scientific sampling frame for a structured sampling (Lalor, 1999). Most of the street children in this study came from the rural area and were away from their families. The sample was recruited by convenient sampling, both from the public streets and from the governmental institution for street children the Protection and Education Center for Street Children in Shanghai (PECSC). ${ }^{1}$ Given that the Center is just a temporary shelter for most of the children, there is significant variation in the number of children staying at the Center at different time. In 2005, during the first 10 days of June, August, and September, all the children in the center were invited to participate in this study. The children were informed of the research objectives and strategies for protecting confidentiality. Their participation was voluntary. In the first round of data collection in the center, 19 street children who were illiterate were interviewed by the researcher, and 17 street children completed the questionnaire by themselves. The counterpart numbers in the second round are 24

\footnotetext{
1 The PECSC is established and managed by the government. It provides basic food, accommodation, and medical care to the street children admitted. The service is temporary as the Center would try to contact the children's parents or guardians and send the children back home. Street children may voluntarily approach the centre for help or they may be forcefully brought to the center by law enforcement officials (e.g., the police). According to the laws and regulations of China, government officials patrolling the streets are obliged to transfer street children they find in the streets to the PECSC regardless of the street children's interest.
} 
and 21 , and 13 and 11 in the third round. Of the 49 questionnaires completed by the children themselves, 21 were identified as valid. Together with other 56 interviewed children, this study obtained 77 valid questionnaires from the center in total. Eleven other samples were recruited from the streets. These 11 street children were also the informants of the researchers' other ethnographic research project on street children in Shanghai. Similar to the data collection process at the PECSC, the research aims and strategies for protecting confidentiality were also explained to the potential respondents and participation was voluntary.

\section{Measures}

The questionnaire was composed of items on demographic information, scales measuring subjective well-being, the length of time the respondent had lived on the street, perception of support available, and self-esteem.

Basic demographic information of age, sex, and education were collected. Age was coded as a continuous variable. Education was assessed via the question "Which level of schooling have you achieved?" The options ranged from illiterate to Secondary 3 or above.

Subjective wellbeing of the children was measured by the Student Life Satisfaction Scale (SLSS) (Huebner, 1991) and a Chinese Positive and Negative Affect Scale for Children (CPANAS-C) which was developed from the Positive and Negative Affect Scale for Children (PANAS-C) (Laurent, et al., 1999). Both the SLSS and PANAS-C scales were translated into Chinese by the researchers and the latter was shortened to form the CPANAS-C as some of the terms are not comprehensible by young Chinese children. In a previous study with migrant children in Shanghai by the authors, the Chinese SLSS and CPANAS-C showed a good internal reliability coefficient of 0.75 and 0.87 respectively. 
For the SLSS, respondents were asked how often they had the satisfying feelings. All the items are presented in the Likert-type 1-4 scale ranging from 1 (almost never) to 4 (all the time). The total score of the seven items form an index of global life satisfaction. Thus, the children's global life satisfaction score ranged from 7 (least satisfaction) to 28 (most satisfaction). The 20-item CPANAS-C is made up of two sub-scales, the first 10 items are words showing positive affect, and other 10 items are words of negative affects. Respondents just indicate whether the words describe their affect state one by one. The answer of "Yes" for each positive affect was given a score of 2, and a score of 1 for each negative affect. An answer of "No" was given a score of 1 for each positive affect and a score of 2 for each affect items. Thus, the total score of the positive scale and the negative scale both ranged from 10 to 20 . Higher scores in both SLSS and CPANAS-C reflect better SWB.

Length of street life experience was measured via the question "How long have you lived or/and worked in the streets?" Six response options were provided to this question: 10 days and below; 11-30 days; 1-6 months; 6-12 months; 1-2 years; and more than 2 years. The answers were later regrouped for analysis. (See Table 1.)

The street children's social support was assessed by asking the children to respond to the following single-item measure of how often "I feel that no one cares about me" in their experiences of street life. This statement is presented in a Likert scale, with 1 (almost never), 2 (sometimes), 3 (a lot of the time), and 4 (all the time). Responses were recoded such that 1 reflects the lowest level of social support while 4 denotes the highest level. The children's self-esteem was assessed by asking them to answer how often "I feel I am no good." This single-item measure was presented in the same Likert scale, and also recoded with 1 representing the lowest level of self-esteem and 4 the highest level. 


\section{Results}

Demographic variables

Demographic information of the examined street children is presented in Table 1. As can be seen, street boys significantly outnumbered (90.9\% vs. $9.1 \%)$ street girls in the sample, which is also true of all street children in China in general (MCA, 2003). According to some of the informants' report, the reason why the number of street girls is so small is because many street girls are "concealed" by illegal people to work as prostitutes or sex slaves. The sample's age distribution is similar to the findings of Liu (2002). Most of the children were aged below 16. The majority of the sample had not been well educated. Almost ninety percent $(88.5 \%)$ of them did not finish the 9-year compulsory education promoted by the Chinese government. This is also consistent with the overall situation of street children in China (MCA, 2003).

Table 1: Demographic variables

\begin{tabular}{|c|c|c|c|c|}
\hline & Variable & Frequency & Percentage & Valid Percentage \\
\hline \multirow{2}{*}{ Sex } & Male & 80 & 90.9 & 90.9 \\
\hline & Female & 8 & 9.1 & 9.1 \\
\hline \multirow{4}{*}{ Age } & 13 and below & 14 & 15.9 & 16.5 \\
\hline & 14 to 15 & 37 & 42 & 43.5 \\
\hline & 16 to 17 & 34 & 38.6 & 40 \\
\hline & Missing & 3 & 3.4 & \\
\hline \multirow{4}{*}{ Education } & Primary 3 and below & 24 & 27.3 & 27.6 \\
\hline & Primary4 to primary 6 & 31 & 35.2 & 35.6 \\
\hline & Form 1 to form 3 & 32 & 36.4 & 36.8 \\
\hline & Missing & 1 & 1.1 & \\
\hline
\end{tabular}

Length of street life history, level of social support and self-esteem

The length of the respondents' street life experience was fairly short overall speaking. More than $60 \%$ of them had spent only 30 days or less on the streets, $25 \%$ of them spent 1-6 months in the streets. Only $11.3 \%$ of them had lived on the streets for more than 6 months. The level of the children's self-esteem was low, with $70 \%$ thinking 
they were "no good" most or all of the time. Their felt social support was more favorable with $30.6 \%$ of them feeling being cared by someone most of the time. (See Table 2.)

Table 2: Length of street life history, level of social support and self-esteem

\begin{tabular}{|c|c|c|c|c|}
\hline & Variable & Frequency & Percentage & Valid Percentage \\
\hline \multirow{5}{*}{$\begin{array}{l}\text { Length of } \\
\text { street life } \\
\text { history }\end{array}$} & 10 days and below & 39 & 44.3 & 48.8 \\
\hline & 11-30 days & 12 & 13.6 & 15 \\
\hline & 1-6 months & 20 & 22.7 & 25 \\
\hline & More than 6 months & 9 & 10.2 & 11.3 \\
\hline & Missing & 8 & 9.1 & \\
\hline \multirow{4}{*}{$\begin{array}{l}\text { Level of } \\
\text { social } \\
\text { support }\end{array}$} & 1(Lowest) & 21 & 23.9 & 24.7 \\
\hline & 2 & 28 & 31.8 & 32.9 \\
\hline & 3 & 10 & 11.4 & 11.8 \\
\hline & 4(Highest) & 26 & 29.5 & 30.6 \\
\hline \multirow{5}{*}{$\begin{array}{l}\text { Level of } \\
\text { self-esteem }\end{array}$} & 1(Lowest) & 32 & 36.4 & 37.2 \\
\hline & 2 & 28 & 31.8 & 32.6 \\
\hline & 3 & 12 & 13.6 & 14 \\
\hline & 4(Highest) & 14 & 15.9 & 16.3 \\
\hline & Missing & 2 & 2.3 & \\
\hline
\end{tabular}

\section{Overall subjective wellbeing}

The street children in the study were not quite satisfied with their life. The mean (15.74) of their general life satisfaction is significantly lower than the neutral point (17.50). This is quite different from findings of existing research works on other populations' overall life satisfaction, Pavot and Diener (1993) found that people's life satisfaction score was generally higher than the neutral point, falling in the slightly satisfied to satisfied range. In this study, the children were frequently harassed by the negative affects. The mean (14.68) of their negative affect score reflected a state poorer than the neutral point (15.00). An interesting finding is that these children obtained a relatively higher score (16.19) in the positive affect, with the neutral point at 15.00. Such a difference between the overall life satisfaction, the negative affect, 
and the positive affect is consistent with existing studies on other populations. A number of studies reported that average levels of positive and negative affects are relatively independent of each other in peoples' lives (Bradburn,1969; Diener \& Emmons, 1985),, and life satisfaction is only moderately related to positive and negative affects (Emmons, 1986). It just reflects that the street children in this study had good feelings towards their life too, while they had a lot of unhappy moments.

Table 3: Means and Standard Deviation of SWB

\begin{tabular}{lccc}
\hline Variable & Valid N & Mean & Std. Deviation \\
\hline Life satisfaction & 81 & 15.74 & 4.33 \\
Positive affect & 81 & 16.19 & 2.07 \\
Negative affect & 77 & 14.68 & 2.04 \\
\hline
\end{tabular}

\section{Predictors of street children's $S W B$}

Further analysis was done to test the hypotheses. ANOVA was used to test the relation between the street children's SWB and their demographic characteristics - age and education. No significant association was found. Street children of different ages and education background in this study were at similar level of SWB. Such result is consistent with the findings of studies on other populations' SWB (Diener, et al., 1997), confirming that the connection between people's SWB and their demographic information is weak. The hypothesis built on the adaptation theory was also not confirmed. There was no significance association between the length of street life history of the street children and their SWB. This was the same with the social support hypothesis. This study has not found significant difference in the SWB of street children with high or low social support. The only factor found to cause significant difference on the children's SWB was their self-esteem level. Although the street children's self-esteem had no significant association with their global life 
satisfaction, it had significant association with their positive affect and negative affect scores. Their higher level of self-esteem was felt by the children, the more positive affect they children experienced $\quad(\mathrm{F}=3.149, \mathrm{p}<0.05)$, and the less negative affect they suffered $(\mathrm{F}=4.094, \mathrm{p}=0.01)$.

Table 4: Analysis of Variance for Self-esteem

\begin{tabular}{|l|l|l|l|}
\hline & df & F & p \\
\hline Positive Affect & 3,75 & 3.149 & 0.03 \\
\hline Negative Affect & 3,71 & 4.094 & 0.01 \\
\hline
\end{tabular}

\section{Discussion}

The main purpose of this study was to explore the marginalized population of street children's overall SWB, and to assess the effect of potential variables on their SWB. ANOVA analysis revealed that demographic factors such as education and age did not significantly influence the street children's SWB. The findings confirmed only two of our four hypotheses outlined earlier. First, the level of the overall SWB of the street children is lower than the general population as both their scores in life satisfaction and negative affection (higher score means less negative affection) were lower than the neutral point. The sampled street children did score a higher level in the Positive Affect. But it looks like their appreciation of their freedom in street life could not make up for the hardship they have to suffer on the street. Second, the street children's level of self-esteem was found to be an important predictor of their positive and negative affects. Specifically, the more the children valued themselves, the more positive affects they experienced, and the less negative affects they suffered. Yet, self-esteem did not significantly influence the children's overall life satisfaction level. Moreover, even though the Shanghai street children often have their social network support (Cheng, 2008), no evidence has been found to support the hypothesis that the 
source of social support influences the children's SWB. The length of time the children had become a street kid also did not significantly influence their SWB. To summarize, though the street children had also happy moments, were able to show resilience in finding their means of living and building their own source of support, their SWB is generally low. Only those with better self-esteem experienced better SWB.

The low SWB of the street children involved in this study could be explained by two possible reasons. The first reason is that satisfaction of basic needs crucially determines SWB at very low levels. According to the Maslow's (1970) theory on hierarchy of needs, physiological needs have to be met before people move for higher level of psychosocial satisfactions. In the ethnographic study of Cheng (2006), it was found that most of the street children in Shanghai suffered from hunger, cold, illness, and psychological uncertainty. The earning capacity of children is limited as they are underage. The length of period they stay in the street does not help very much with their income. Maybe it is only until they become of age to join the labor force that their situation could improve, and by then, they would have left the street. Just like street children in other countries (West, 2003), Shanghai street children are also subject to physical and psychological abuse by others (Cheng, 2008). Short of protection from the legal system or responsible adults, the limited social support they generate among themselves might not effectively mitigate the negative effect of suffering and harassments they encounter. Absolute poverty and environmental factors might have a stronger influence on these street children's SWB which cannot be explained by the adaptation theory.

A second possible reason for the Shanghai street children's low level SWB is their lack of responsible and caring parents. In many cities like Calcutta of India and Phnom Penh of Cambodia, Ho Chi Ming city of Vietnam, some street children have 
their families to turn to. They are children from poor families looking for income on the street in the day time, and they go home in the evening. But for the Shanghai street children in this study, all of them come from outside the city. They are practically homeless and they have no access to parental support. Some of them actually left home because of their parents' abuse and neglect. These children experienced strong sense of abandonment and helplessness (Cheng, 2008). So their sense of SWB could be worse as they have even thinner resources.

Whatever the specific reason is, it is the right of children to be provided with basic life necessities and protection. Reducing their chance of experiencing hunger, cold, and violence would lower their negative affect and improve their SWB. Since the children's self-esteem has been found positively related to their SWB, services such as psychological counseling or street life training which may improve their self-esteem level would also contribute to their SWB.

This study has actually revealed the bright side of these street children's life. They reported experience of positive affects although they were not satisfied with their life. Rather than presenting how completely miserable the street children's life is, it may be more appropriate to describe their everyday life as a multiple-dimension complex. Happiness, freedom, and other positive affects coexist with sorrow, loneliness, and other negative affects. What kind of role have such positive affects played in the street children's decision of staying on the street? Programs designed to help the children leave the streets and to integrate them into mainstream society need to take this point into account.

Two limitations with this study need to be acknowledged and addressed. The first 
limitation concerns the measures of subjective wellbeing. The internal reliability of the Chinese version of Student Life Satisfaction Scale (SLSS) and the Chinese Positive and Negative Affect Scale for Children (CPANAS-C) have only been tested in the population of migrant children in Shanghai. Those migrant children generally lived with their parents and went to school. They actually had a different childhood from that of that of the street children. Yet, given the fact that it is difficult to find enough number of street children to do the reliability test, and that both the street children and the migrant children were from rural China and lived in Shanghai, the tools were adopted.

The second limitation has to do with sampling. The study only used convenient sampling as street children could not be easily approached for study. A trust issue is involved and there is also much interference on the street. So the number of respondents recruited from the street was small. The largest pool of sample available was at the PECSC. The cooperation of the staff of the Shanghai PECSC must be acknowledged. But still the population was limited. The sample size (88) is rather small. The findings could not be broadly generalized. Because the number of children recruited from the public streets was small, comparison between the children from the streets and from the center also was also not possible. The study can only serve as an initial exploration of the Shanghai street children's overall SWB, and also the potential predictors of their SWB.

As a follow-up from this study, it can be seen that some research questions are worthy of further investigation in the future. If a bigger population can be reached, further testing of the various hypotheses may still be worthy, especially with the control of age, and length of street life experience. Even self-esteem was found to be significantly related to the street children's level of positive and negative affects in this study, it could only explain about five percent of the variance of the positive 
affect and nine percent of the negative affect. It is not clear how other factors might have influenced the SWB of the street children. Although two possible reasons for the children's low level SWB are provided, additional research is needed to verify the propositions. A longitudinal study of their life could trace better their changes in their state of SWB as they stay longer on the street. The impact of tough life on the development of these children is not totally clear. These children's tough life journey is accompanied by both positive and negative affects. It is surely worthy to find out if most of the street children ultimately become more resilient normal working adults, or just get drifted to join the criminal gangs.

\section{References}

Ayerst, S. L. (1999) 'Depression and stress in street youth', Adolescence 34(135):567-575.

Bar-On, A. (1997) ‘Criminalising survival: Images and reality of street children’, Journal of Social Policy 26(1): 63-78.

Beers, H. V. (1996) 'A plea for a child-centered approach in research with street children', Childhood 3(2):195-201.

Biswas-Diener, R., \& Diener, E. (2006) 'The subjective well-being of the homeless, and lessons for happiness', Social Indicators Research 76(2):185-205.

Cheng, F. C. (2006) 'The street children's street life and the victimizations against them: an ethnographic study', Youth Studies (in Chinese) 9: 1-9.

Cheng, F. C. (2008) 'Negotiating exclusion: an ethnographic study of the street children in Shanghai, China', Hong Kong: Unpublished doctoral dissertation, The University of Hong Kong.

Diener, E. (1994) 'Assessing subjective wellbeing: Progress and opportunities', Social 
Indicators Research 31(2):103-157.

Diener, E., \& Diener, C. (1996) 'Most people are happy', Psychological Science 7(3):181-185.

Diener, E., \& Seligman, E. P. (2004) 'Beyond money: toward an economy of well-being', Psychological Science in the Public Interest 5(1): 1-31.

Diener, E., Suh, E., \& Oishi, S. (1997) 'Recent findings on subjective well-being'. Retrieved March 27, 2006, from http://www.psych.uiuc.edu/ ediener/hottopic/paper1.html.

Diener, E., \& Suh, E. M. (2000). Culture and subjective well-being. Cambridge, Mass. ; London: MIT Press.

Donald, D., \& Swart-Kruge, J. (1994) 'The South African street child: Developmental implications', The South African Journal of Psychology 24(4): 169-174.

Emmons, R. A. (1986) 'Personal strivings: An approach to personality and subjective well-being', Journal of Personality and Social Psychology 51(5): 1058-1068.

Huebner, E. S. (1991) 'Initial development of the student's life satisfaction scale', School Psychology International 12(3): 231-240.

Judge, T. A., Erez, A., Bono, J. E., \& Thoresen, C. J. (2002) ‘Are measures of self-esteem, neuroticism, locus of control, and generalised self-efficacy indicators of a common core construct?', Journal of Personality and Social Psychology 83(3): 693-710.

Kidd, S. A. (2003) 'Street youth: Coping and interventions', Child and Adolescent Social Work Journal 20(4): 235-261.

Lalor, K. (1999) 'Street children: a comparative perspective', Child Abuse and Neglect 23 (8): 759-770.

Laurent, J., Catanzaro, S. J., Rudolph, K. D., \& Joiner, T. E. J. (1999) 'A measure of positive and negative affect for children: Scale development and preliminary 
validation', Psychological Assessment 11(3): 326-338.

Liu, J. T. (2002) 'A case study of the Help and Protection Center for Street Children in Zhenzhou', Youth Studies(in Chinese) 1: 30-39.

Maslow, A. H. (1970) Motivation and personality (2nd ed.). New York: Harper \& Row.

MCA. (2003) ‘A report of working with street children', Retrieved June 11, 2004, from http://www.mca.gov.cn/artical/content/WTG_YWJS/200443185205.HTML.

Mirsky, J. (1997) 'Psychological distress among immigrant adolescents: culture-specific factors in the case of immigrants from the former Soviet Union', International Journal of Psychology 32(4): 221-230.

Neto, F. (2001) 'Satisfaction with life among adolescents from immigrant families in Portugal', Journal of Youth and Adolescence 30(1): 53-67.

Putnam, R. D. (2000). Bowling alone : the collapse and revival of American community. New York: Simon \& Schuster.

Roy, M., Neale, M. C., \& Kendler, K. S. (1995) 'The genetic epidemiology of self-esteem', British Journal of Psychiatry 166(6): 813-820.

Turner, R. J. (1981) 'Social support as contingency in psychological well-being', Journal of Health and Social Behavior 22(4): 357-367.

West, A. (2003). At the margins: Street children in Asia and the Pacific. Poverty and Social Development Paper No. 8. Asian Development Bank. Retrieved August 202009 from http://www.adb.org/Documents/Papers/Street_children_Asia_Pacific/SC_final.p df 